\title{
Revealing Austenite Stability in Fe-30Mn-5Al-0.5C Twinning-Induced Plasticity Steel Using Differential Thermal Analysis
}

\author{
David M. Bastidas, * Sebastián F. Medina, Jacob Ress, José A. Jiménez, \\ and José M. Bastidas
}

The thermal stability of austenite in as-cast high-alloyed Fe-30Mn-5Al-0.5C twinning-induced plasticity (TWIP) steel has been studied by differential thermal analysis (DTA). TWIP steels are subjected to austenization treatments in the temperature range between 800 and $1200^{\circ} \mathrm{C}$ and holding times between 3 and $100 \mathrm{~min}$. Different heating and cooling rate conditions are applied, including cooling rates between 0.1 and $1.0 \mathrm{~K} \mathrm{~s}^{-1}$ and three heating rates $0.08,0.33$, and $0.83 \mathrm{~K} \mathrm{~s}^{-1}$. The DTA results show that austenite is stable for all of the heat treatments applied. Microstructural analysis reveals a strong dendritic segregation due to the high percentages of Mn and Al in the composition of the TWIP steel. Finally, the austenitization temperature significantly influences the austenite grain size, unlike the cooling and heating rates that have an insignificant effect. The DTA results are confirmed by the $\mathrm{X}$-ray diffraction analysis, revealing a single-phase $\gamma$-austenite crystal structure.

\section{Introduction}

Steel is the most widely used material in automotive industry, particularly for car bodies, and makes up $99 \%$ of the passenger protection zone and $60-70 \%$ of the rest of the vehicle parts. ${ }^{[1]}$ Twinning-induced plasticity (TWIP) steels are classified as second-generation advanced high strength steels (AHSS). TWIP steels are lightweight, thus contributing to reduced energy consumption. Therefore, the development of TWIP steels helps to reduce greenhouse gas emissions and decelerate climate change. ${ }^{[2]}$ Compared with the first-generation steels (dual phase [DP], transformation-induced plasticity [TRIP], complex phase

Prof. D. M. Bastidas, J. Ress

Department of Chemical, Biomolecular, and Corrosion Engineering

National Center for Education and Research on Corrosion and Materials

Performance

NCERCAMP-UA

The University of Akron

302 E Buchtel Ave, Akron, OH 44325-3906, USA

E-mail: dbastidas@uakron.edu

Prof. S. F. Medina, Dr. J. A. Jiménez, Prof. J. M. Bastidas

National Center for Metallurgical Research (CENIM)

CSIC

Ave. Gregorio del Amo 8, 28040 Madrid, Spain

The ORCID identification number(s) for the author(s) of this article can be found under https://doi.org/10.1002/srin.202000076.

DOI: 10.1002/srin.202000076
[CP], and martensitic [MART] steels), TWIP steels have greater strength and formability; however, large-scale applications are limited because they are strongly alloyed steels, resulting in higher costs and greater technical difficulties in the manufacturing process. ${ }^{[3]}$

TWIP steel is produced by a small number of companies, namely, Nippon Steel, Kobe Steel, Korean Posco Company, and Thyssen Krupp Stahl German. One of the major applications of low-carbon TWIP steel is for car bodies, showing a ductility (elongation) greater than $90 \%$. Highcarbon TWIP steels (0.5 wt\% C) such as $\mathrm{Fe}-30 \mathrm{Mn}-5 \mathrm{Al}-0.5 \mathrm{C}$ reach an ultimate strength of $1200 \mathrm{MPa}$ and a ductility of $70 \%$ at temperatures below $100{ }^{\circ} \mathrm{C}$, being very useful for the manufacture of automotive components. These mechanical properties are unique to TWIP steel and not achieved by any other type of steel. ${ }^{[4-6]}$

TWIP steel presents a stable austenitic structure at room temperature. The high Mn content between 15\% and 30\% promotes a single-phase austenite microstructure. Mechanical deformation induces twinning, thus initiating the phase transformation of a fraction of $\gamma$-austenite, a face-centered cubic (fcc) structure, into $\varepsilon$-martensite which has a hexagonal close packed (hcp) structure and/or $\alpha^{\prime}$-martensite, with body-centered cubic (bcc) structure. ${ }^{[7,8]}$ Furthermore, for low Mn composition, a fraction of $\gamma$-austenite can be transformed into $\alpha$-ferrite.

The presence of both $\alpha$-ferrite and $\varepsilon$-martensite is not beneficial due to the decrease in mechanical strength and ductility. In addition, $\alpha$-ferrite and $\varepsilon$-martensite crystal structures are detrimental for corrosion resistance in TWIP steel alloys. ${ }^{[9]}$ To avoid the formation of $\varepsilon$-martensite during the plastic deformation processes (rolling, forging, extrusion), $\mathrm{Al}$ is added as an alloying element. $^{[10-13]}$ The presence of $\mathrm{Al}$ increases the stacking fault energy (SFE), thus avoiding the $\gamma \rightarrow \varepsilon$ phase transformation. Therefore, the Al improves the formability of TWIP steel. Moreover, the deformation twins prevent dislocation movement and necking is suppressed due to strain hardening. The high $\mathrm{Al}$ content ( $5 \mathrm{wt} \%$ ) of $\mathrm{Fe}-30 \mathrm{Mn}-5 \mathrm{Al}-0.5 \mathrm{C}$ TWIP steel produces a high SFE value, greater than $20 \mathrm{~mJ} \mathrm{~m}^{-2}$, preventing $\varepsilon$-martensite formation. Among all possible deformation modes for austenitic steels, TWIP offers the most beneficial effect during strain hardening. ${ }^{[4]}$ 
The aim of the present work is to study the stability of austenite in a high-alloyed Fe-30Mn-5Al-0.5C TWIP steel with casting structure, which presents a strong dendritic segregation. The vast dendritic segregation shown in as-cast high-alloyed Fe-30Mn5Al-0.5C TWIP steel can be reduced by hot rolling, whereas cold rolling and subsequent annealing will slightly decrease the degree of dendritic segregation. Various heat treatments have been conducted using different austenitization temperatures and holding times. In addition, the influence of heating and cooling rates on the austenite phase stability was also investigated.

\section{Experimental Section}

Fe-30Mn-5Al-0.5C TWIP steel has been prepared by induction melting high purity (99.98\%) electrolytic Fe and $\mathrm{Mn},(99.95 \%) \mathrm{Al}$, and graphite in an alumina crucible under $40 \mathrm{kPa}$ of argon as protective gas environment and casting into a copper mould $24 \mathrm{~mm}$ in diameter. Table 1 shows the chemical composition analysis by spark optical emission spectroscopy (OES), showing a high Mn content of $30 \mathrm{wt} \%$.

Differential thermal analysis (DTA) was conducted in a SETARAM (SETSYS model) thermal analyzer. ${ }^{[14]}$ The DTA analyzer was equipped with a graphite furnace cooled by external water flow, graphite resistors, and two $\mathrm{Al}_{2} \mathrm{O}_{3}$ crucibles for reference and analysis samples. A cylindrical sample $3.3 \mathrm{~mm}$ in diameter and $5.5 \mathrm{~mm}$ in length was analyzed. Experiments were conducted using an S-type thermocouple (Pt/PtRh 10\%) for temperature measurements between 50 and $1200^{\circ} \mathrm{C}$. The oven was vacuum purged prior to testing, reaching a pressure between $2.0 \times 10^{-4} \mathrm{MPa}$ and $10.0 \times 10^{-4} \mathrm{MPa}$. The furnace atmosphere was controlled by argon flow.

The temperature difference $(\Delta T)$ was recorded by two thermocouples placed on the test and reference samples. The DTA results were plotted using either $\Delta T$ or $\Delta V$, depending on the temperature $(T)$ of the reference sample.

It should be noted that the dilatometric technique is also appropriate for the detection of phase transformations, especially when high cooling and heating rates are applied. However, due to its greater sensitivity, the DTA technique was used in this study because it is more useful when small transformations or reactions occur in volume percentages below $5 \%$.

Microstructure analysis was conducted on each of the Fe-30Mn-5Al-0.5C TWIP specimen. Samples were embedded in bakelite, roughened, polished with $0.1 \mu \mathrm{m}$ diamond powder solution, and finally etched with $20 \%$ Nital. The microstructures resulting from the different heat treatments were observed by optical microscopy (OM).

To confirm the stability of austenite and to reveal crystallographic phases, X-ray diffraction (XRD) analysis was performed using a Bruker AXS D8-Discover diffractometer, equipped with a Co $\mathrm{K} \alpha$ radiation anode, with a wavelength of $1.7902 \AA$, operating at a voltage of $40 \mathrm{kV}$ and a current of $30 \mathrm{~mA}$. The XRD patterns

Table 1. Chemical composition of the Fe-30Mn-5Al-0.5C TWIP steel (wt\%).

\begin{tabular}{lcccccc}
\hline Element & $\mathrm{Mn}$ & $\mathrm{Al}$ & $\mathrm{C}$ & $\mathrm{S}$ & $\mathrm{P}$ & $\mathrm{Fe}$ \\
\hline Content [wt\%] & 30 & 5 & 0.5 & 0.01 & $<0.01$ & Balance \\
\hline
\end{tabular}

were recorded under conventional $\theta-2 \theta$ scans from $35^{\circ}$ to $125^{\circ}$ with a step size of $0.02^{\circ}$. The lattice parameter of the austenite was determined by Rietveld refinement using the software TOPAS-v4.2.

Finally, a JEOL JSM-6500F field emission scanning electron microscope (FE-SEM) coupled with an energy-dispersive X-ray (EDX) spectrometer were used to study casting defects during solidification process in Fe-30Mn-5Al-0.5C TWIP steel such as dendritic segregation, as well as element composition. An accelerating voltage of $20.0 \mathrm{kV}$ was used with a working distance of $10.0 \mathrm{~mm}$.

\section{Results and Discussion}

Microstructure analysis of as-cast specimens revealed dendrites and interdendritic spaces that correspond to a typical solidification microstructure without subsequent thermal or thermomechanical treatment (see Figure 1).

\subsection{DTA}

DTA results of Fe-30Mn-5Al-0.5C TWIP steel were obtained using test conditions, as shown in Table 2. The influence of heat treatment conditions was studied by varying parameters including five different holding temperatures $(800,900,1000,1100$, and $\left.1200^{\circ} \mathrm{C}\right)$, three heating rates $\left(0.08,0.33\right.$, and $\left.0.83 \mathrm{~K} \mathrm{~s}^{-1}\right)$, four holding times $(3,10,30$, and $100 \mathrm{~min})$, and four different cooling rates $\left(0.1,0.2,0.5\right.$, and $\left.1.0 \mathrm{~K} \mathrm{~s}^{-1}\right)$.

The DTA plots of Figure 2 consist of heating and cooling curves, drawn in black, and the derivatives curves from the previous tests in blue; both are labeled with arrows to indicate the direction of heating and cooling. Figure 2 shows DTA plots for Fe-30Mn-5Al-0.5C TWIP steel samples obtained using the same $0.33 \mathrm{~K} \mathrm{~s}^{-1}$ heating rate and $3 \mathrm{~min}$ holding time, with varying austenitization temperature and cooling rate. Figure 2a,b shows the DTA curves obtained for the highest $\left(1.0 \mathrm{~K} \mathrm{~s}^{-1}\right)$ and the lowest $\left(0.1 \mathrm{~K} \mathrm{~s}^{-1}\right)$ cooling rate applied, respectively. Figure $2 \mathrm{c}$, d shows the DTA curves for the lowest $\left(800^{\circ} \mathrm{C}\right)$ and the highest $\left(1200^{\circ} \mathrm{C}\right)$ austenitization temperature tested, respectively.

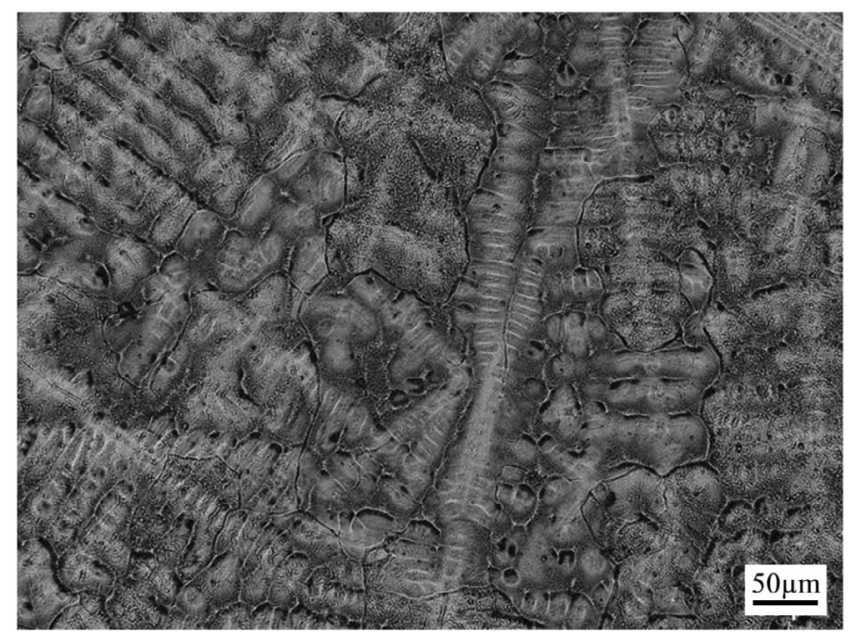

Figure 1. Optical micrograph of as-cast Fe-30Mn-5Al-0.5C TWIP steel. 
Table 2. Heating treatment applied during DTA test.

\begin{tabular}{lcccc}
\hline Sample & $\begin{array}{c}\text { Temperature } \\
{\left[{ }^{\circ} \mathrm{C}\right]}\end{array}$ & $\begin{array}{c}\text { Heating } \\
\text { rate }\left[\mathrm{K} \mathrm{s}^{-1}\right]\end{array}$ & $\begin{array}{c}\text { Holding } \\
\text { time }[\mathrm{min}]\end{array}$ & $\begin{array}{c}\text { Cooling } \\
\text { rate }\left[\mathrm{K} \mathrm{s}^{-1}\right]\end{array}$ \\
\hline 1 & 1000 & 0.33 & 3 & 1.0 \\
2 & 1000 & 0.33 & 3 & 0.5 \\
3 & 1000 & 0.33 & 3 & 0.2 \\
4 & 1000 & 0.33 & 3 & 0.1 \\
5 & 800 & 0.33 & 3 & 0.2 \\
6 & 900 & 0.33 & 3 & 0.2 \\
7 & 1100 & 0.33 & 3 & 0.2 \\
8 & 1200 & 0.33 & 3 & 0.2 \\
9 & 1000 & 0.33 & 10 & 0.2 \\
10 & 1000 & 0.33 & 30 & 0.2 \\
11 & 1000 & 0.33 & 100 & 0.2 \\
12 & 1000 & 0.08 & 3 & 0.2 \\
13 & 1000 & 0.83 & 3 & 0.2 \\
\hline
\end{tabular}

Figure 3 shows DTA plots for Fe-30Mn-5Al-0.5C TWIP steel using a $1000^{\circ} \mathrm{C}$ holding temperature and $0.2 \mathrm{~K} \mathrm{~s}^{-1}$ cooling rate, with varying holding times and heating rate. Furthermore, Figure 3a,b shows holding times of 10 and $100 \mathrm{~min}$, respectively. Finally, Figure $3 \mathrm{c}, \mathrm{d}$ shows the DTA results for heating rate values of 0.08 and $0.83 \mathrm{~K} \mathrm{~s}^{-1}$, respectively. Among the temperature range studied, an intermediate temperature of $1000^{\circ} \mathrm{C}$ was selected because it enables hot rolling and casting processes to be applied.
At $1000^{\circ} \mathrm{C}$ the dendritic microstructure of the as-cast high-alloyed Fe-30Mn-5Al-0.5C TWIP steel remains stable.

In Figure 2 and 3, the increase in heat flux $(\mathrm{HF}, \mu \mathrm{V})$ between both crucibles, containing test and reference samples, is lower and approaches zero as the temperature increases. A difference in $\mathrm{HF}$ of $50 \mu \mathrm{V}\left(5^{\circ} \mathrm{C}\right)$ between both thermocouples can be observed when the temperature reaches $600^{\circ} \mathrm{C}$. Figure $3 \mathrm{~d}$ shows the DTA plot with the highest heating rate tested, $0.83 \mathrm{~K} \mathrm{~s}^{-1}$, showing an enhanced HF difference between reference and test samples.

DTA test results represent the extreme conditions applied during TWIP steel manufacturing process, i.e., maximum and minimum values of each of the different test parameters, cooling rate and heating rate, higher and lower austenitization temperature, and holding time. An absence of transformation peaks was observed for all the specimens tested, thus demonstrating the stability of austenite.

\subsection{Microstructures}

DTA analysis of Fe-30Mn-5Al-0.5C TWIP steel shows that the austenite phase is stable despite the different experimental conditions applied. After the metallographic preparation indicated earlier, the microstructures were imaged by OM.

Figure 4 shows the microstructures of the different as-cast specimens tested using same heating rate $\left(0.33 \mathrm{~K} \mathrm{~s}^{-1}\right)$ and holding time ( $3 \mathrm{~min})$. A dendritic microstructure was found in all specimens (Figure $4 \mathrm{a}-\mathrm{c}$ ), which remained unaltered after the heat treatments during DTA testing, excluding Figure 4d, which
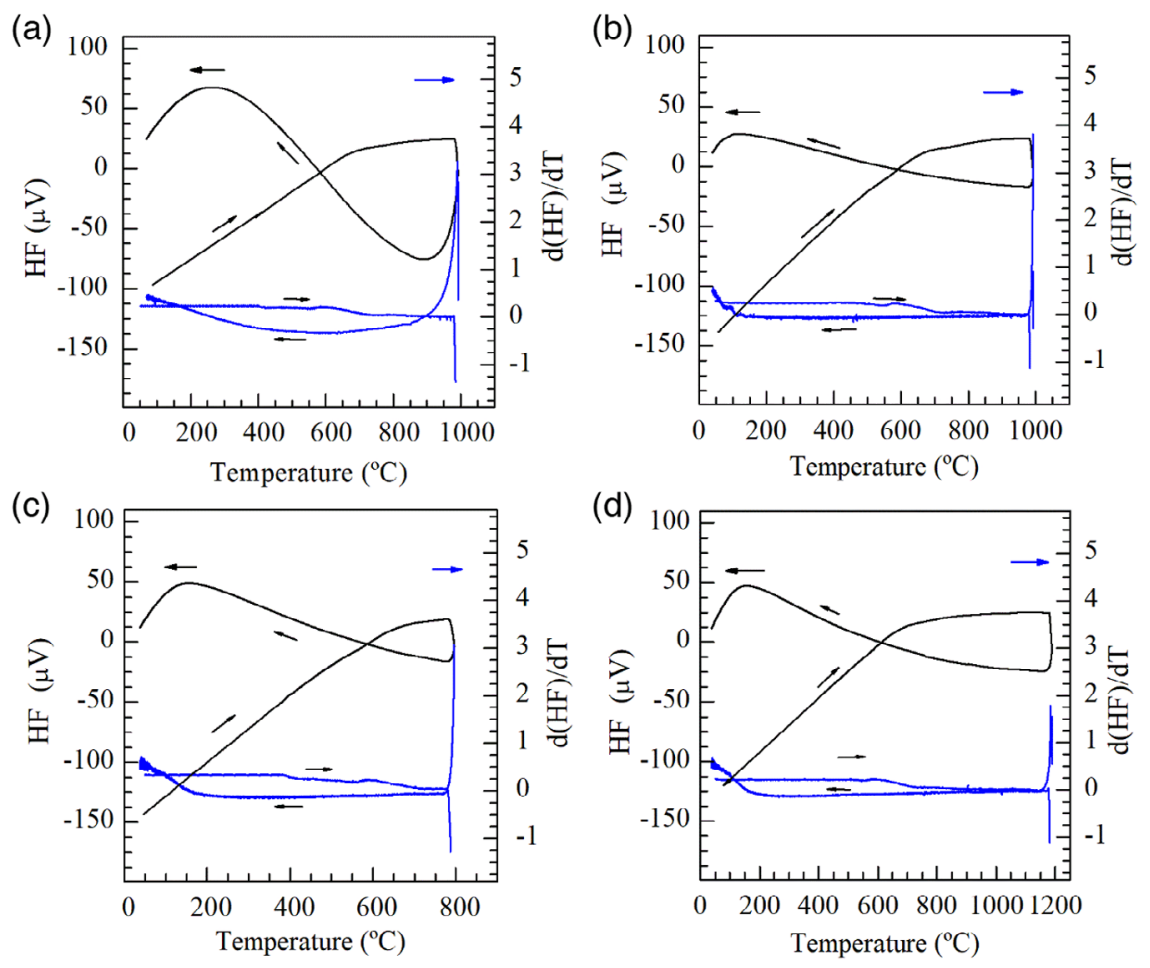

Figure 2. DTA plots of Fe-30Mn-5Al-0.5C TWIP steel samples obtained using the same $0.33 \mathrm{~K} \mathrm{~s}^{-1}$ heating rate and 3 min holding time, varying austenitization temperature, and cooling rate: a) sample 1 at $1000^{\circ} \mathrm{C}$ and $0.1 \mathrm{~K} \mathrm{~s}^{-1}$ cooling rate, b) sample 4 at $1000^{\circ} \mathrm{C}$ and $0.1 \mathrm{~K} \mathrm{~s}^{-1}$ cooling rate, c) sample 5 at $800^{\circ} \mathrm{C}$ and $0.2 \mathrm{~K} \mathrm{~s}^{-1}$ cooling rate, and d) sample 8 at $1200^{\circ} \mathrm{C}$ and $0.2 \mathrm{~K} \mathrm{~s}^{-1}$ cooling rate. 

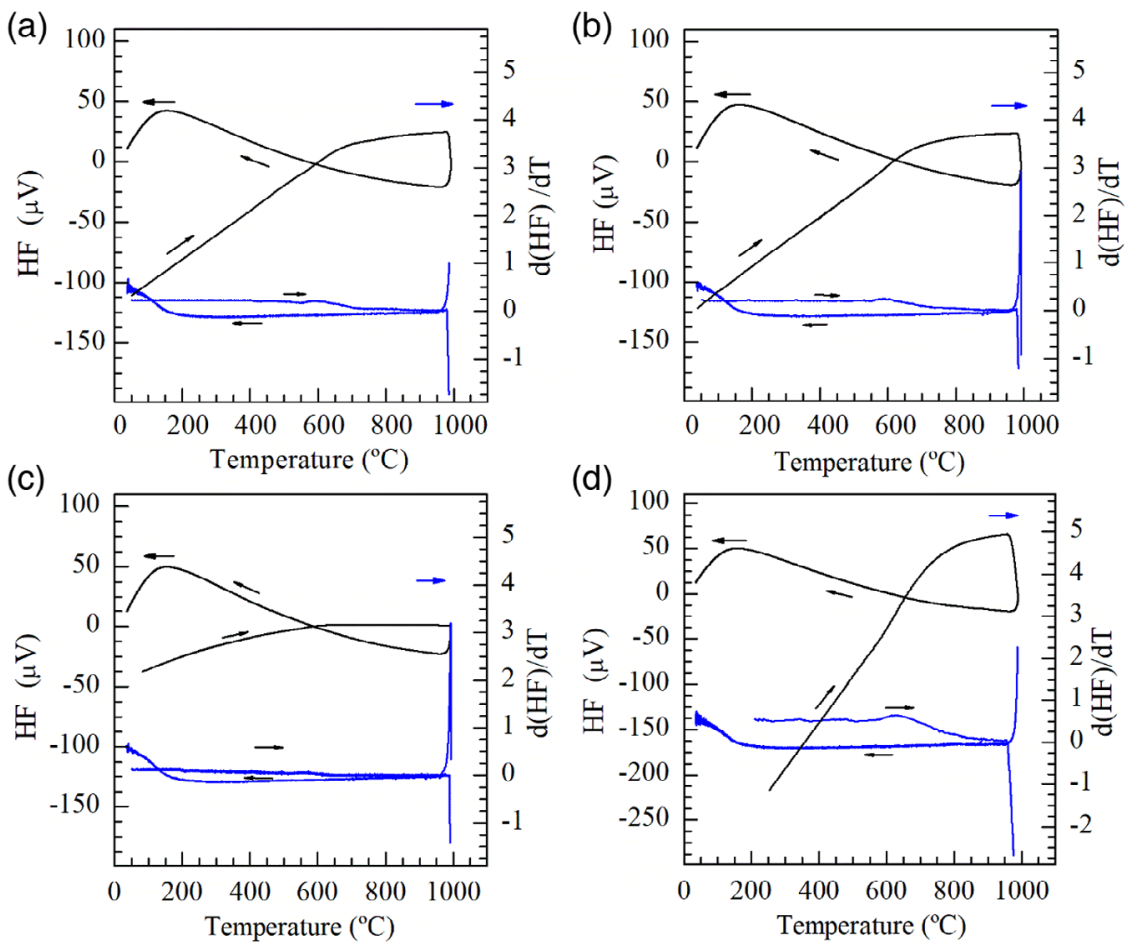

Figure 3. DTA plots of Fe-30Mn-5Al-0.5C TWIP steel using a $1000^{\circ} \mathrm{C}$ holding temperature and $0.2 \mathrm{~K} \mathrm{~s}^{-1}$ cooling rate, varying holding times, and heating rate: a) sample 9 used $10 \mathrm{~min}$ holding time and $0.33 \mathrm{~K} \mathrm{~s}^{-1}$ heating rate, b) sample 11 used 100 min holding time and $0.33 \mathrm{~K} \mathrm{~s}^{-1}$ heating rate, c) sample 12 used $3 \mathrm{~min}$ holding time and $0.83 \mathrm{~K} \mathrm{~s}^{-1}$ heating rate, and d) sample 13 used 3 min holding time and $0.83 \mathrm{~K} \mathrm{~s}^{-1}$ heating rate.
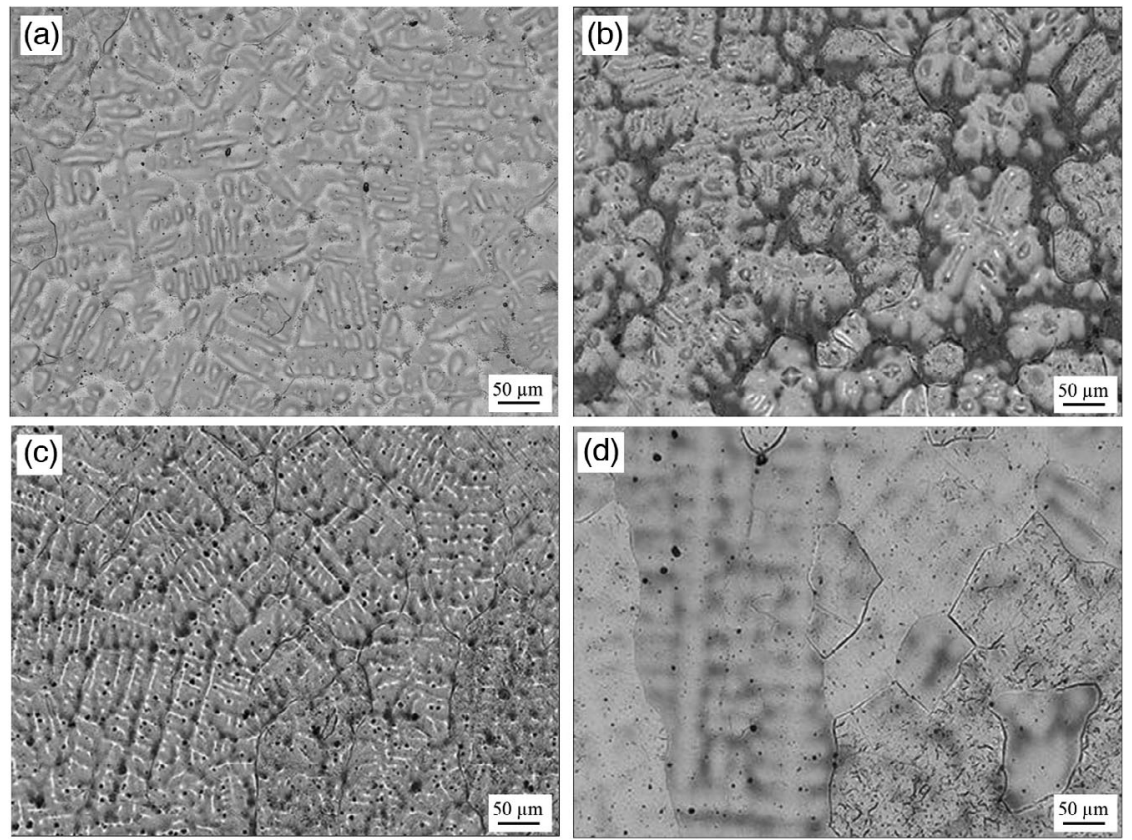

Figure 4. SEM micrographs of Fe-30Mn-5Al-0.5C TWIP steel samples obtained using the same $0.33 \mathrm{~K} \mathrm{~s}^{-1}$ heating rate and 3 min holding time, varying austenitization temperature, and cooling rate: a) sample 1 at $1000^{\circ} \mathrm{C}$ and $0.1 \mathrm{~K} \mathrm{~s}^{-1}$ cooling rate, b) sample 4 at $1000^{\circ} \mathrm{C}^{\text {and }} 0.1 \mathrm{~K} \mathrm{~s}{ }^{-1}$ cooling rate, c) sample 5 at $800^{\circ} \mathrm{C}$ and $0.2 \mathrm{~K} \mathrm{~s}^{-1}$ cooling rate, and d) sample 8 at $1200^{\circ} \mathrm{C}$ and $0.2 \mathrm{~K} \mathrm{~s}^{-1}$ cooling rate.

shows a weak formation of dendritic microstructure due to the diffusion of $\mathrm{C}, \mathrm{Mn}$, and $\mathrm{Al}$ elements from the interdendritic region to the dendritic arms at $1200^{\circ} \mathrm{C}$. In most cases, the austenitization temperature was chosen to be $1000^{\circ} \mathrm{C}$, which has 
proven to be insufficient to enable the diffusion of the alloy elements to achieve uniform chemical composition, therefore the dendritic microstructure is similar in all the specimens which correspond to the same austenitization temperature of $1000^{\circ} \mathrm{C}$ (see Figure 4a,b).

Figure 5 shows dendritic microstructures obtained for TWIP samples treated at $1000^{\circ} \mathrm{C}$ and cooled down at same cooling rate $\left(0.2 \mathrm{~K} \mathrm{~s}^{-1}\right)$. The complete transformation of the dendritic microstructure to cellular microstructure would require longer times and temperatures close to $1200{ }^{\circ} \mathrm{C}$ for diffusion processes to be enhanced. Therefore, transition from columnar to equiaxed microstructure would require sample deformation and strain hardening beforehand and, subsequently, high-temperature recrystallization annealing.

\subsection{Austenite Grain Size}

The grain size (GS) was measured following the ASTM E112-13 standard; ${ }^{[15]}$ the results are shown in Figure 6. The temperature greatly influences the growth of the austenite grain. After heat treatment at $800^{\circ} \mathrm{C}$ for $3 \mathrm{~min}$, the obtained GS number was 6 (see Figure 6a), which corresponds to an average austenite grain diameter $\left(d_{\gamma}\right)$ of $45 \mu \mathrm{m}$. However, the heat treatment at $1200^{\circ} \mathrm{C}$ for $3 \mathrm{~min}$ produced a GS number of 3 (see Figure 6a), corresponding to a $d_{\gamma}$ of $127 \mu \mathrm{m}$.

The size of the dendrites varied depending on whether the dendrites were primary, secondary, or tertiary dendrites, whose size is decreasing in that order. Regardless, the length of the primary dendrites does not normally exceed $500 \mu \mathrm{m}$. Interdendritic spacing values ranging between 15 and $60 \mu \mathrm{m}$ was obtained for primary dendrites.
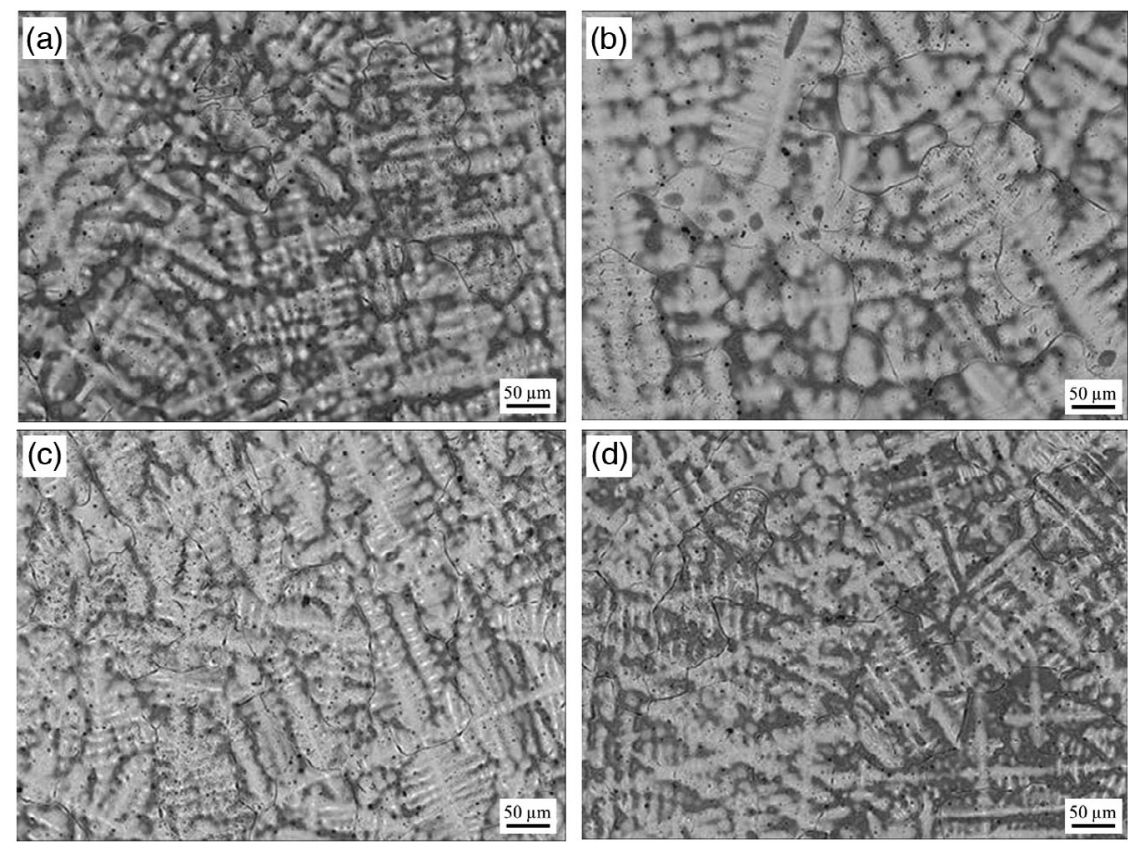
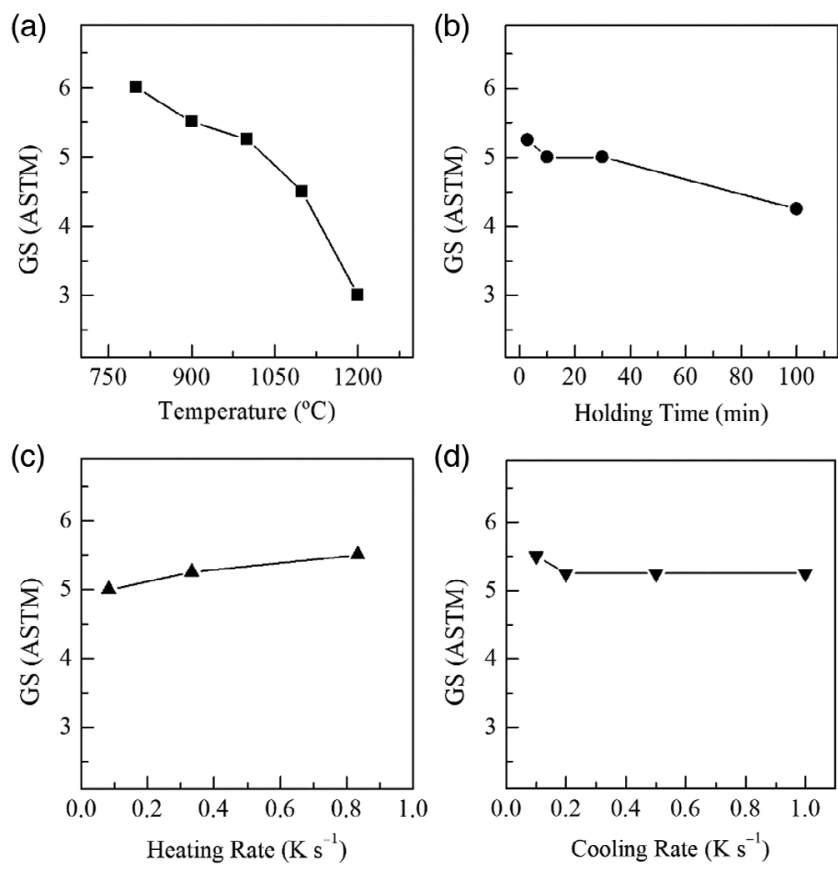

Figure 6. Austenite GS of Fe-30Mn-5Al-0.5C TWIP steel obtained with varying a) temperature, b) holding time, c) heating rate, and d) cooling rate.

Nucleation of twins on the grain boundaries is favored by smaller austenite grain size. On TWIP steels with high Mn content, the twins generated during deformation produce dislocations pinning, which facilitates grain boundary refinement,

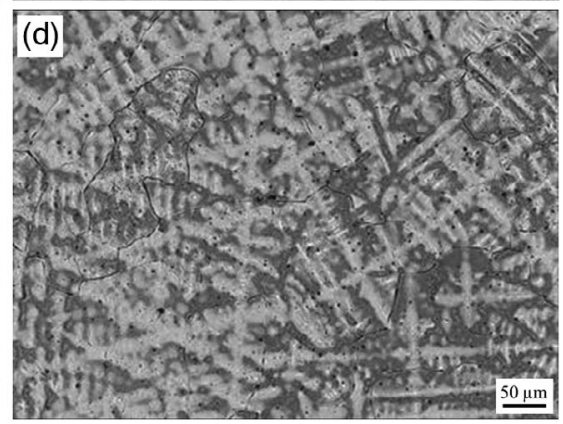

Figure 5. SEM micrographs of Fe-30Mn-5Al-0.5C TWIP steel samples obtained using the same austenitization temperature of $1000^{\circ} \mathrm{C}$ and $0.2 \mathrm{~K} \mathrm{~s}^{-1}$ cooling rate, varying heating rate, and holding times: a) sample 9 at $0.33 \mathrm{~K} \mathrm{~s}^{-1}$ heating rate and 10 min holding time, b) sample 11 at $0.33 \mathrm{~K} \mathrm{~s}{ }^{-1}$ heating rate and $100 \mathrm{~min}$ holding time, c) sample 12 at $0.08 \mathrm{~K} \mathrm{~s}^{-1}$ heating rate and $3 \mathrm{~min}$ holding time, and d) sample 13 at $0.83 \mathrm{~K} \mathrm{~s}^{-1}$ heating rate and 3 min holding time. 
a phenomenon known as Hall Petch dynamic effect. ${ }^{[4]}$ As indicated earlier, the austenite grain grows notably as the temperature increases, which can affect the mechanical properties.

The results of Figure 6 show that, for an optimized manufacturing process of the Fe-30Mn-5Al-0.5C TWIP steel, it is required to have a small austenite grain size to promote deformation twinning. This suggests a certain complexity in the thermomechanical treatments, as diffusion annealing increases the GS, which hinders reaching an appropriate density of deformation twins, thus affecting the mechanical properties. ${ }^{[16,17]}$ Rahman et al. ${ }^{[18]}$ showed that the best mechanical strength and impact toughness of TWIP steels with a smaller austenitic grain size is due to the smaller thickness of the twins, which decreases as the grain size decreases. A higher stacking fault density for TWIP steels with a larger austenitic grain was also observed. Therefore, the different manufacturers of TWIP steel protect the specific heat and thermomechanical treatments applied to their products using patents.

\subsection{XRD Analysis}

To confirm that single-phase austenite structure is present in Fe-30Mn-5Al-0.5C TWIP steel, XRD analysis was performed on two samples subjected to extreme temperatures such as samples 5 and 8 , heated to 800 and $1200^{\circ} \mathrm{C}$ for holding time of $3 \mathrm{~min}$, respectively (see Figure 7a,b).

XRD patterns revealed a single-phase austenite structure, where GS values of 45 and $127 \mu \mathrm{m}$ were determined for samples 5 and 8 , respectively. Moreover, the same lattice parameter for both specimens was calculated to be $0.3655 \mathrm{~nm}$ using the Rietveld refinement method. This value is slightly higher than

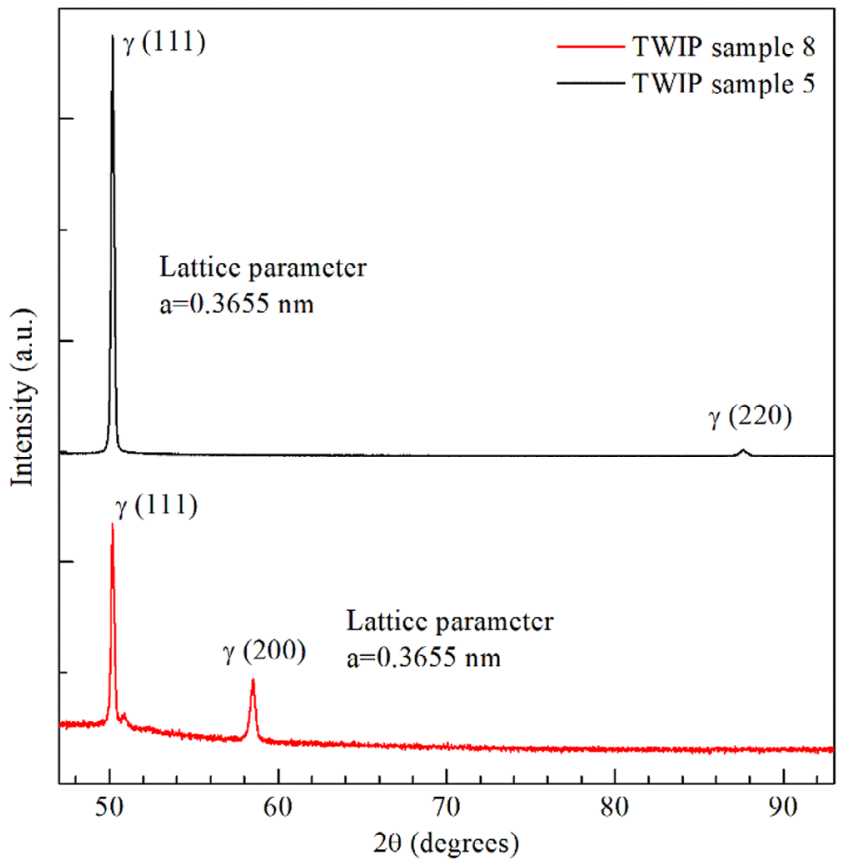

Figure 7. XRD patterns of Fe-30Mn-5Al-0.5C TWIP steel obtained using $0.33 \mathrm{~K} \mathrm{~s}^{-1}$ heating rate, $3 \mathrm{~min}, 0.2 \mathrm{~K} \mathrm{~s}^{-1}$ cooling rate, varying austenitization temperatures, sample $5\left(800^{\circ} \mathrm{C}\right)$, and sample $8\left(1200^{\circ} \mathrm{C}\right)$. the expected lattice parameter for the austenite structure of a TWIP steel with $0.5 \mathrm{wt} \% \mathrm{C}$ without any other alloying element, which is $0.3631 \mathrm{~nm}$, according to Onink et al. ${ }^{[19]}$ The slightly larger lattice parameter is attributed to high concentrations of manganese (30 wt\% $\mathrm{Mn}$ ) and aluminum (5 wt\% $\mathrm{Al})$, with atoms occupying substitutional sites.

\subsection{EDX Microanalysis}

The high percentages of $\mathrm{Mn}$ and $\mathrm{Al}$ in $\mathrm{Fe}-30 \mathrm{Mn}-5 \mathrm{Al}-0.5 \mathrm{C}$ TWIP steel enhance the formation of a dendritic microstructure during solidification and, consequently, produce a microsegregation with interdendritic regions rich in solute compared with the dendrites. The EDX microanalysis allows elemental composition of the dendrites and the interdendritic spaces to be determined. To overcome differences in the composition because microsegregation, the alloys would require long-term annealing at high temperatures, thus greatly increasing the manufacturing cost of the TWIP steels. EDX microanalysis was performed on sample 3 (Table 2), which was heated to $1000^{\circ} \mathrm{C}$ for $3 \mathrm{~min}$ and cooled at a rate of $0.2 \mathrm{~K} \mathrm{~s}^{-1}$.

First, the EDX microanalysis was performed on a dendrite as shown in Figure 8, and the results (spectrum 1) are $66.69 \mathrm{wt} \%$ $\mathrm{Fe}, 4.94 \mathrm{wt} \% \mathrm{Al}$, and $27.37 \mathrm{wt} \% \mathrm{Mn}$, where the percentage of $\mathrm{Mn}$ is below the average concentration of the element in the Fe-30Mn-5Al-0.5C TWIP steel (30 wt\% Mn). Similarly, an EDX microanalysis was performed on the interdendritic region as shown in Figure 9, and the results (spectrum 2) are $57.87 \mathrm{wt} \% \mathrm{Fe}, 5.11 \mathrm{wt} \% \mathrm{Al}$, and $37.02 \mathrm{wt} \% \mathrm{Mn}$, where aluminum content was found to be average for the Fe-30Mn-5Al-0.5C TWIP steel ( $5 \mathrm{wt} \% \mathrm{Al}$ ); however, manganese significantly exceeded the average content (30 wt\% Mn). These results show that the differences in composition between dendrites and interdendritic spaces are minimal with respect to $\mathrm{Al}$, and somewhat larger with respect to $\mathrm{Mn}$.

Despite the heat treatment at $1000{ }^{\circ} \mathrm{C}$ for $3 \mathrm{~min}$ applied to sample 3, it was not enough to homogenize the composition with

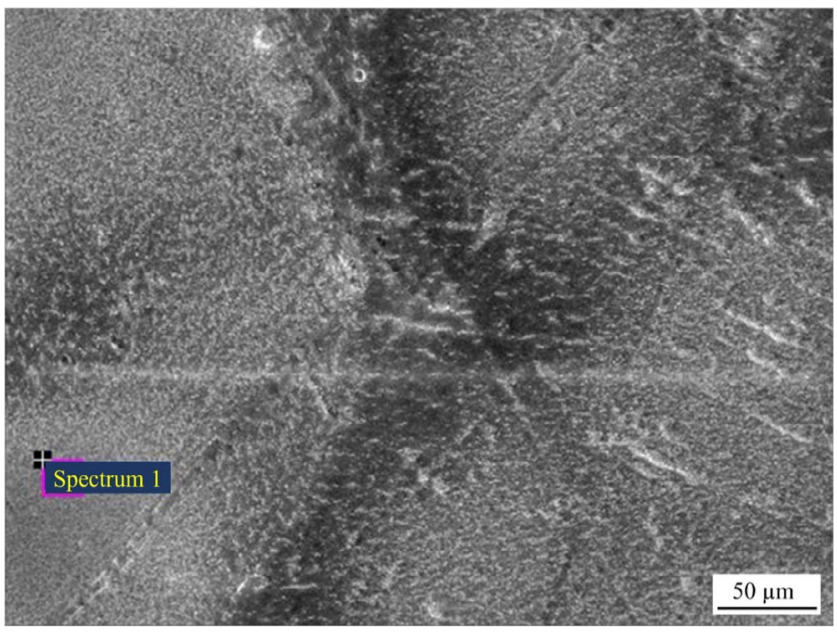

Figure 8. SEM image of a dendrite on Fe-30Mn-5Al-0.5C TWIP steel. EDX analysis of area "spectrum 1," with 66.69 wt\% Fe, 4.94 wt\% Al, and $27.37 \mathrm{wt} \% \mathrm{Mn}$. 


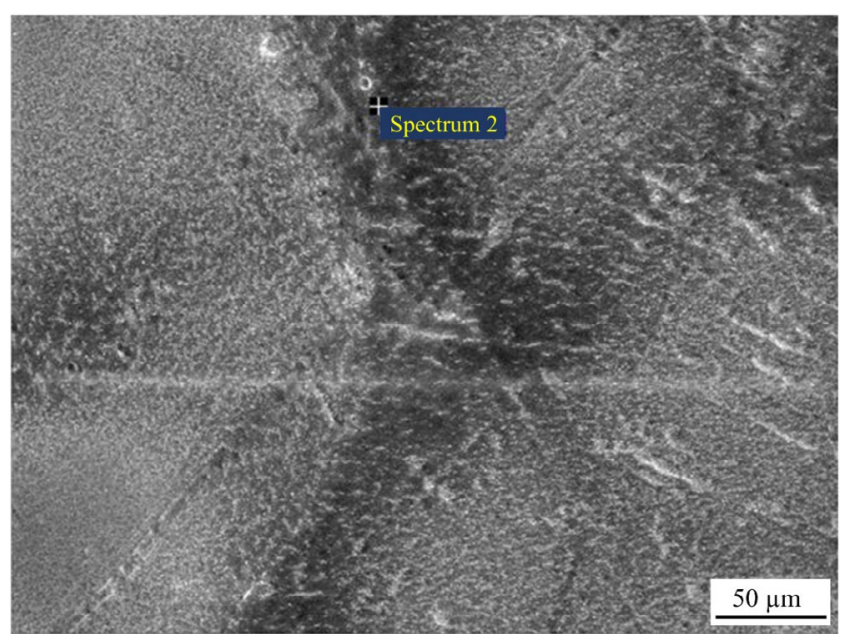

Figure 9. SEM image of an interdendritic region on Fe-30Mn-5Al-0.5C TWIP steel. EDX analysis of area "spectrum 2," with $57.87 \mathrm{wt} \% \mathrm{Fe}$, $5.11 \mathrm{wt} \% \mathrm{Al}$, and $37.02 \mathrm{wt} \% \mathrm{Mn}$.

respect to $\mathrm{Mn}$, although the $\mathrm{Al}$ distribution was homogeneous. This is due to the diffusion coefficients of both $\mathrm{Al}$ and Mn elements (see Equation (1) and (2)) in austenite $(\gamma$-Fe), showing the diffusion of $\mathrm{Mn}$ in austenite is more than two orders of magnitude lower than that of $\mathrm{Al}$ (see Figure 10) agreeing with the general Arrhenius expression: ${ }^{[20,21]}$

$D_{\mathrm{Al}}\left(\mathrm{m}^{2} \mathrm{~s}^{-1}\right)=1.80 \times 10^{-4} e^{-\frac{228.20}{R T}}$

$D_{\mathrm{Mn}}\left(\mathrm{m}^{2} \mathrm{~s}^{-1}\right)=0.16 \times 10^{-4} e^{-\frac{261.70}{R T}}$

where $D_{\mathrm{Al}}$ and $D_{\mathrm{Mn}}$ are the diffusion coefficient of $\mathrm{Al}$ and Mn elements, respectively, $1.80 \times 10^{-4}$ and $0.16 \times 10^{-4}\left(\mathrm{~mol} \mathrm{~m}^{-2} \mathrm{~s}^{-1}\right)$

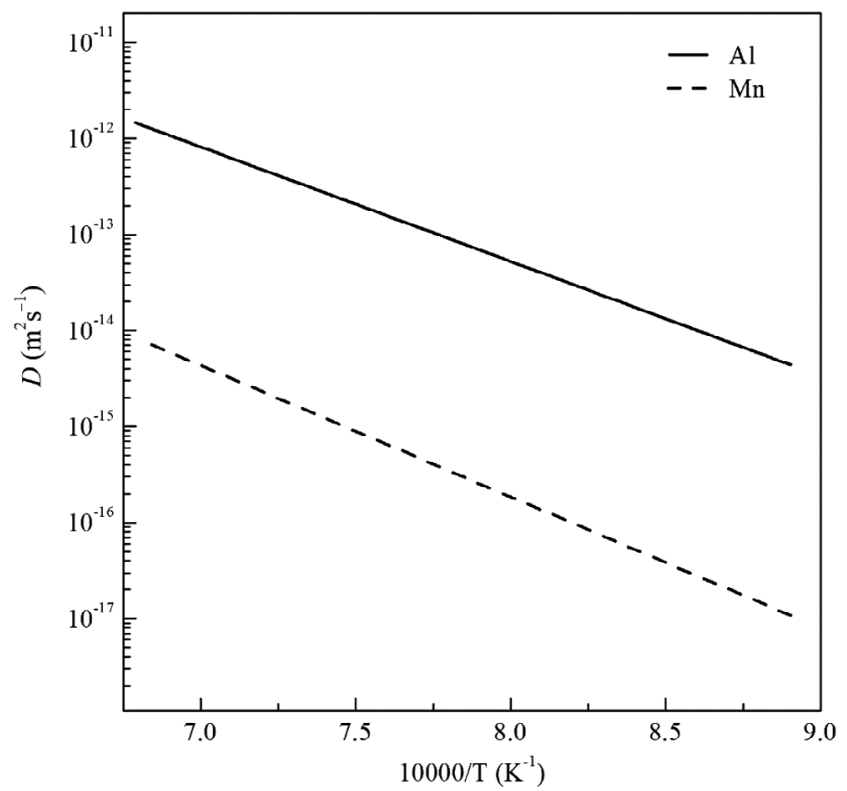

Figure 10. Plot of diffusion coefficients $(D)$ of $A l$ and $M n$ against the inverse of temperature $\left(\mathrm{K}^{-1}\right)$. are the frequency factor, 228.20 and $261.70\left(\mathrm{~kJ} \mathrm{~mol}^{-1}\right)$ are the activation energy, $R\left(\mathrm{~kJ} \mathrm{~mol}^{-1} \mathrm{~K}^{-1}\right)$ is the molar gas constant, and $T(\mathrm{~K})$ is the absolute temperature.

In addition to the larger frequency factor in Equation (1), the activation energy for the diffusion of $\mathrm{Al}$ into austenite is markedly lower than that of Mn. Thus, the obtained value of $D_{\mathrm{Al}}$ is higher than $D_{\mathrm{Mn}}$, regardless of temperature.

\section{Conclusions}

1) The DTA technique shows that Fe-30Mn-5Al-0.5C TWIP steel presents a stable single-phase austenite structure, regardless of heat treatments. Therefore, considering as-cast specimens with dendritic microsegregation, it can be said that austenite stability is absolute. 2) The grain size increases remarkably with temperature, being much less sensitive to changes in holding time. High alloying element contents (Mn, Al) decelerate diffusion in grain boundaries. 3) XRD analysis has confirmed that as-cast Fe-30Mn-5Al-0.5C TWIP steel has a single-phase austenite structure. The austenite stability has been shown for different austenitization temperatures, heating and cooling rates, as well as for numerous holding times applied during experimental DTA conditions.

\section{Acknowledgements}

D.M.B. and J.R. acknowledge funding from The University of Akron, Fellowship Program FRC-207367.

\section{Conflict of Interest}

The authors declare no conflict of interest.

\section{Keywords}

austenite, dendritic microstructures, differential thermal analysis, twinning-induced plasticity steel, X-ray diffraction

Received: February 15, 2020

Revised: April 13, 2020

Published online: May 4, 2020

[1] B. C. De Cooman, K.-G. Chin, J. Kim, New Trends and Developments in Automotive System Engineering (Ed: M. Chiaberge), InTech Europe, Rijeka 2011, pp. 101-128.

[2] J. Galan, L. Samek, P. Verleysen, K. Verbeken, Y. Houbaert, Rev. Metal. Madrid 2012, 48118.

[3] J. Zhao, Z. Jiang, Prog. Mater. Sci. 2018, 94174.

[4] O. Bouaziz, S. Allain, C. P. Scott, P. Cugy, D. Barbier, Solid State Mater. Sci. 2011, 15141.

[5] O. Bouaziz, S. Allain, C. Scott, Scr. Mater. 2008, 58484.

[6] O. Bouaziz, N. Guelton, Mater. Sci. Eng. A 2001, 319246.

[7] O. Grassel, L. Kruger, G. Frommeyer, L. W. Meyer, Int. J. Plast. 2000, 16, 1391.

[8] Y.-K. Lee, C. Choi, Metall. Mater. Trans. A 2000, 31, 355.

[9] S. Fajardo, I. Llorente, J. A. Jimenez, J. M. Bastidas, D. M. Bastidas, Corros. Sci. 2019, 154, 246.

[10] K. Ishida, T. Nishizawa, Trans. Jpn. Inst. Met. 1974, 15, 225. 
[11] S. Hong, J. Lee, B. J. Lee, H. S. Kim, S. K. Kim, K. G. Chin, S. Lee, Mater. Sci. Eng. A 2013, 587, 85.

[12] L. Mujica-Roncery, S. Weber, W. Theisen, Metall. Mater. Trans. A 2010, 412471.

[13] D. T. Pierce, J. A. Jimenez, U. J. Bentley, D. Raabe, J. E. Wittig, Acta Mater. 2015, 100, 178.

[14] A. Pastor, P. Valles, S. F. Medina, Steel Res. Int. 2017, 88, 1600229.

[15] ASTM E112-13 Standard, Standard Test Methods for Determining Average Grain Size, ASTM International, West Conshohocken, PA 2013.
[16] I. Gutierrez-Urrutia, S. Zaefferer, D. Raabe, Mater. Sci. Eng. A 2010, $527,3552$.

[17] Y. H. Wen, H. B. Peng, D. Raabe, I. Gutierrez-Urrutia, J. Chen, Y. Y. Du, Nat. Commun. 2014, 5, 4964.

[18] K. M. Rahman, V. A. Vorontsov, D. Dye, Acta Mater. 2015, 89, 247.

[19] M. Onink, C. M. Brakman, F. D. Tichelaar, E. J. Mittemeijer, S. van der Zwaag, Scr. Metal. Mater. 1993, 29, 1011.

[20] A. D. Le Claire, G. Neumann, Diffusion in Solid Metals and Alloys (Ed: H. Mehrer), Springer, Berlin, Vol. 26, 1991.

[21] H. Oikawa, Tetsu-to-Hagane 1982, 68, 1489. 